\title{
WHITETAILS AND THE 1979-80 WINTER IN SASKATCHEWAN
}

HUGH HUNT, Dept. of Tourism and Renewable Resources, 2602 8th Street East, Saskatoon, Saskatchewan, S7H OV7, FREDERICK LEIGHTON and GARY WOBESER, Dept. of Veterinary Pathology, Western College of Veterinary Medicine, University of Saskatchewan, Saskatoon, Saskatchewan. S7N OWO.

For the past several years, winter mortality of white-tailed deer in Saskatchewan has been monitored in a joint investigation by the Wildlife Research Division of the Department of Tourism and Renewable Resources and the Department of Veterinary Pathology of the Western College of Veterinary Medicine. White-tailed deer found dead by DTRR field staff during the winter were examined to measure their physical condition and to determine the factors causing and/or contributing to their death.

The study's findings in the most recent winter (1979-1980) are unique in several respects, presumably reflecting winter conditions in the province. Subjectively, the 1979-80 winter can be described as mild and relatively short throughout most of Saskatchewan. Snow pack in much of agricultural Saskatchewan was near or below the long-term average, daily temperatures were often higher than average, and winter ended earlier and more quickly than usual with a warm late March and an unusually warm April. For example, weather data collected by the Saskatchewan Research Council at Saskatoon indicate average or above average monthly mean temperatures for the Saskatoon area in November, December, February, and April along with a 13-day warm spell in January and a shorter one in late March. Lower-than-average mean wind speeds through the entire winter precluded acute wind chill values. Although Saskatoon received somewhat more snow than average, temperatures above freezing in each month helped to lessen the snow pack.

The mildness of the 1979-1980 winter was evident in the total of only 35 white-tailed deer submitted for necropsy compared to totals 3 to 5 times higher in the more severe 1973$1974,1975-1976$, and 1978-1979 winters. Most of the specimens $(82.8 \%)$ had died as a result of collisions with automobiles (77.1\%) or trains $(5.7 \%)$ (Table 1$)$; this type of mortality was 2 to 4 times more important than was the case in more severe winters. Predation accounted for two deaths, starvation for one, and the cause of death was unclear in three instances. In both cases of predation, domestic dogs were the predators and the deer were only maimed in the attacks. The deer were subsequently shot. During winters characterized by deeper snow than in 1978-1979, predator kills, principally by dogs, have accounted for up to a third of the specimens submitted. Starvation, of little consequence as a cause of mortality in the mild 19791980 winter, was more prevalent in the more severe winters, particularly 1973-1974.

Body condition estimates for each 
TABLE 1: Cause of death of white-tailed deer specimens obtained during the 1979-80 winter.

$\begin{array}{lrc}\text { Mortality Factor } & \begin{array}{c}\text { No. of } \\ \text { Deer }\end{array} & \begin{array}{c}\% \text { of } \\ \text { Sample }\end{array} \\ \text { Automobile Collision } & 27 & 77.1 \\ \text { Train Collision } & 2 & 5.7 \\ \text { Predation } & 2 & 5.7 \\ \text { Starvation } & 1 & 2.9 \\ \text { Unknown } & 3 & 8.6 \\ \text { Total } & 35 & 100.0 \%\end{array}$

specimen, based on the amount of fat remaining in the carcass at the time of death, indicated the adult deer were in good body condition even late in the 1979-1980 winter and fawn deer had been able to maintain good body condition noticeably longer than in severe winters. The pregnancy rate of $60 \%$ (6 of 10 ) for fawn females was 2 to 3 times higher than has been recorded during severe winters.

Gross examination of rumen or stomach contents to describe winter diets revealed that woody browse was the principal food of almost $80 \%$ of the 1979-1980 deer. Cereal grains were the principal food of the remainder of the deer. Cereal grains and tame forages made up less of the diet of whitetails in the 1979-80 winter than in more severe winters, presumably because the mild weather conditions and shallow snow depths did not restrict the availability of natural foods. This suggests that white-tailed deer in the wild prefer natural foods over agricultural crops as their principal winter diet, given adequate supplies of each.

A complete assessment of the significance of the various causes of winter mortality of white-tailed deer was beyond the scope of our investigation. For example, deer dying from vehicle collisions were presumably over-represented in the sample because of the greater chance of discovery of these specimens in comparison to those animals dying from predation, starvation, or disease. However, factors such as the types of mortality occurring, body condition, pregnancy rates, and diets do provide some insight into the influence of each winter on the provincial deer herd. These indicators suggest the 1979-80 winter was a relatively easy winter for whitetailed deer in Saskatchewan.

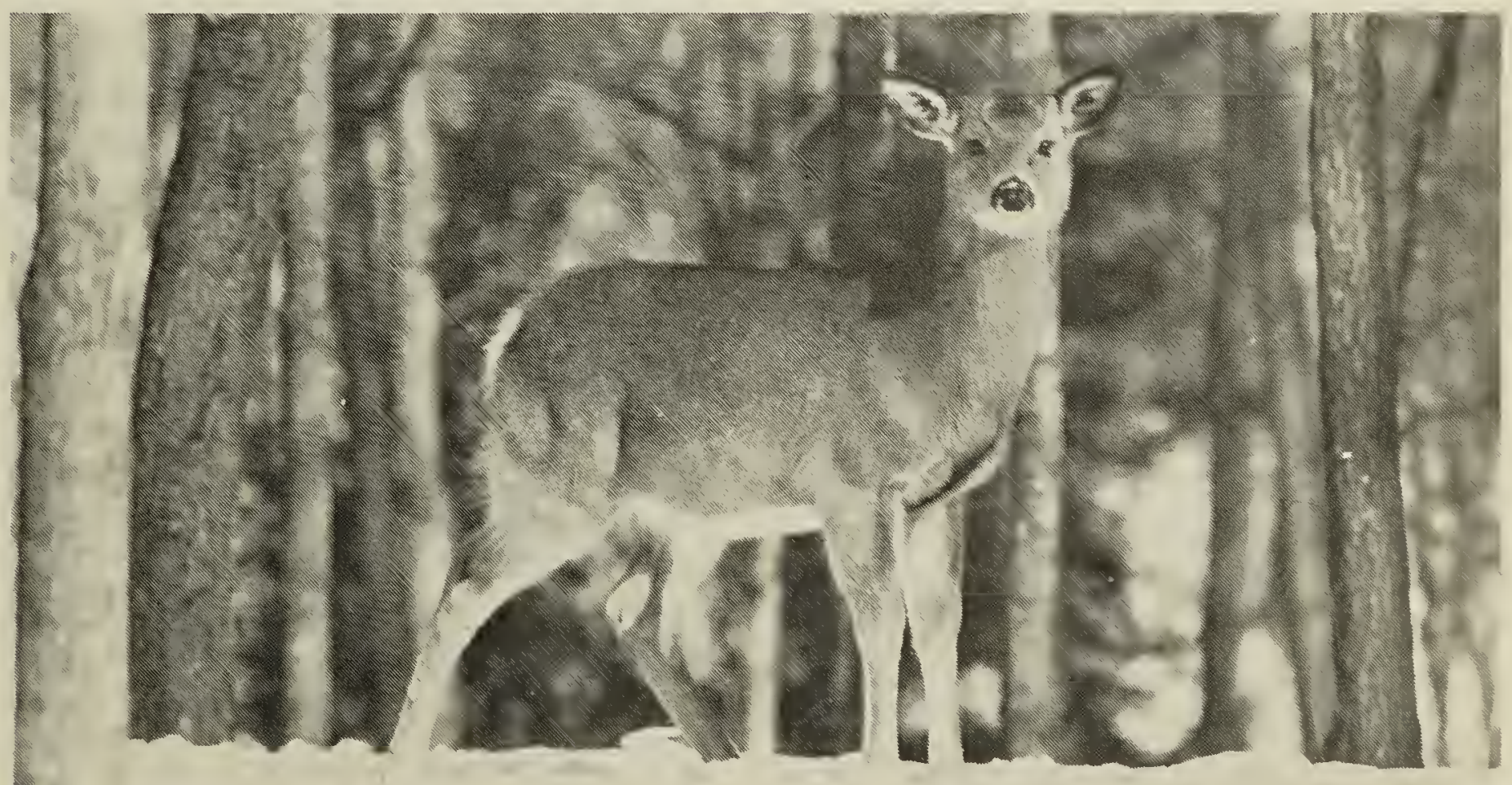




\section{UNUSUAL WHITE-TAILED DEER BEHAVIOR}

JAMES A. CARSON, 565 Linden Avenue, Winnipeg, Manitoba, R2K 0N9.

While bowhunting for deer in the Winnipeg vicinity on the evening of 10 November 1979, at approximately 1630 , I made an unusual observation which I should like to record. What I saw was unusual in the sense that l've never seen it before during eight years hunting white-tailed deer in similar circumstances, nor have I ever read anything approaching it.

I had my tree stand set some 40 paces from two buck scrapes on the edge of a bluff or grove of trees. The habitat consisted of a mixture of oak, ash, elm and maple. Secondary growth was hazel and chokecherry. The area was fairly open. From 12 feet up in my stand I could see a fair distance in all directions. The ground had a light cover of snow which increased the capability of observing all nearby animal movements (Diagram no. 1).

Two white-tailed deer appeared. One was a doe, quite large, the other, which was smaller, appeared to be a yearling doe (spring 1979). When the two animals got within 50 yards or so, the smaller doe trotted over to one of the scrapes, meanwhile shaking its head from side to side. Upon reaching the scrape, she proceeded to jump up and down on it with all four feet lifting off the ground at the same time. Ears bent forward, legs very stiff, and tail straight in the air, she made a peculiar sight (Diagram no. 2).

She repeated this four times, then started biting at the branches above the scrape, virtually trying to break them off higher up, above what had been broken previously. Seconds later she kicked leaves and grass in a frenzy of activity. Scampering and playing like a dog, retreating from the scrape for several yards, then within the same moment running back to the scrape, neck stretched, nose down and smelling the bare ground. As she approached, she extended her front legs forward, hunching her back like a dog stretching, and shuffled backwards at a rapid pace. Doing this

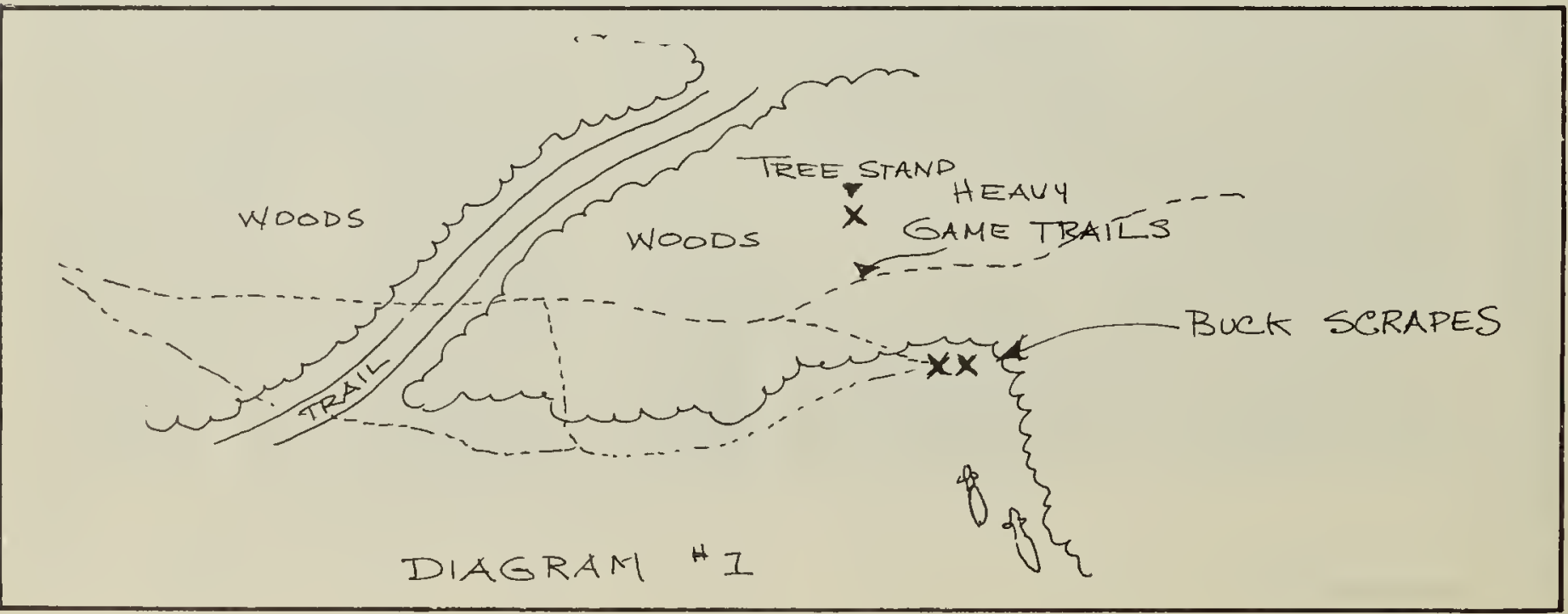




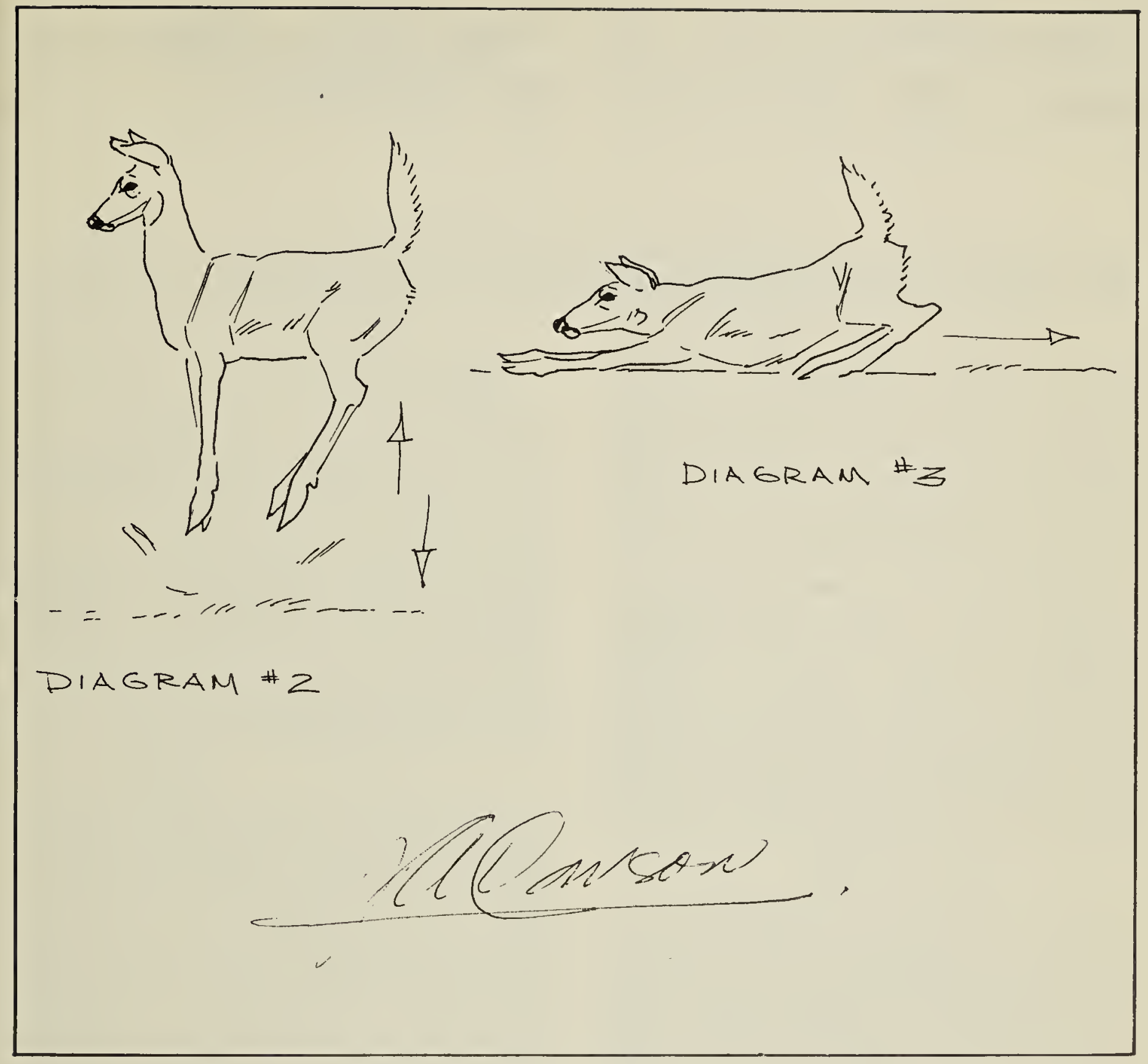

twice, she returned to the scrape to jump on it three more times with the stiff-legged posture. Then she walked away for several feet, urinating on the trail. She then ran down the trail in a terrific burst of speed, disappearing from sight (Diagram no. 3).

The larger doe approached the scrape at a walk and proceeded to bite the branches and paw the ground. She performed basically the same actions of those of the younger animal, but with more premeditated movements. At the end of the sequence she urinated in the middle of the scrape, turned, smelled the urine, and again with a sudden burst of energy followed the younger doe and disappeared.

\section{SASKATCHEWAN CHRISTMAS MAMMAL COUNT}

Reports of mammals seen during the Christmas Bird Counts will be compiled again this year. When making your Christmas Bird Count, please note the number of each species of mammal seen, and the species of tracks that you can positively identify.

Send the list with your Bird Count by January 15,1981 , at the latest, to Mrs. Mary I. Houston, 863 University Drive, Saskatoon, Sask. S7N 0J8. 